Open Access

\title{
Appraisal of systemic inflammation and diagnostic markers in a porcine model of VAP: secondary analysis from a study on novel preventive strategies
}

Gianluigi Li Bassi ${ }^{1,2,3,4 \dagger}$, Raquel Guillamat Prats ${ }^{3,5+}$, Antonio Artigas ${ }^{3,5}$, Eli Aguilera Xiol 1,2,3, Joan-Daniel Marti ${ }^{1}$, Otavio T. Ranzani ${ }^{1}$, Montserrat Rigol ${ }^{1,2,6}$, Laia Fernandez ${ }^{1,2,3,4}$, Andrea Meli ${ }^{1,7}$, Denise Battaglini ${ }^{1,8}$, Nestor Luque $^{1}$, Miguel Ferrer ${ }^{1,2,3,4}$, Ignacio Martin-Loeches ${ }^{9}$, Pedro Póvoa ${ }^{10,11}$, Davide Chiumello ${ }^{7}$, Paolo Pelosi ${ }^{8}$ and Antoni Torres ${ }^{1,2,3,4^{*}}$

\footnotetext{
* Correspondence: atorres@clinic.cat ${ }^{\dagger}$ Gianluigi Li Bassi and Raquel Guillamat Prats contributed equally to this work.

${ }^{1}$ Division of Animal

Experimentation, Department of Pulmonary and Critical Care

Medicine, Thorax Institute, Hospital Clinic, Calle Villarroel 170, Esc 6/8 PI

2, Barcelona, Spain

${ }^{2}$ Institut d'Investigacions

Biomèdiques August Pi i Sunyer (IDIBAPS), Barcelona, Spain

Full list of author information is available at the end of the article
}

\begin{abstract}
Background: We previously evaluated the efficacy of a ventilatory strategy to achieve expiratory flow bias and positive end-expiratory pressure (EFB + PEEP) or the Trendelenburg position (TP) for the prevention of ventilator-associated pneumonia (VAP). These preventive measures were aimed at improving mucus clearance and reducing pulmonary aspiration of bacteria-laden oropharyngeal secretions. This secondary analysis is aimed at evaluating the effects of aforementioned interventions on systemic inflammation and to substantiate the value of clinical parameters and cytokines in the diagnosis of VAP.

Methods: Twenty female pigs were randomized to be positioned in the semirecumbent/ prone position, and ventilated with duty cycle 0.33 and without PEEP (control); positioned as in the control group, PEEP $5 \mathrm{cmH}_{2} \mathrm{O}$, and duty cycle to achieve expiratory flow bias (EFB+PEEP); ventilated as in the control group, but in the Trendelenburg position (Trendelenburg). Following randomization, P. aeruginosa was instilled into the oropharynx. Systemic cytokines and tracheal secretions $P$. aeruginosa concentration were quantified every 24h. Lung biopsies were collected for microbiological confirmation of VAP.

Results: In the control, EFB + PEEP, and Trendelenburg groups, lung tissue Pseudomonas aeruginosa concentration was $2.4 \pm 1.5,1.9 \pm 2.1$, and $0.3 \pm 0.6 \mathrm{log} \mathrm{cfu} / \mathrm{mL}$, respectively $(p$ $=0.020)$. Whereas, it was $2.4 \pm 1.9$ and $0.6 \pm 0.9 \mathrm{log} \mathrm{cfu} / \mathrm{mL}$ in animals with or without VAP $(p<0.001)$. Lower levels of interleukin (IL)-1 $\beta(p=0.021)$, IL-1RA $(p<0.001)$, IL-4 $(p=0.005)$, IL-8 $(p=0.008)$, and IL-18 $(p=0.050)$ were found in Trendelenburg animals. VAP increased IL-10 ( $p=0.035)$, tumor necrosis factor-a $(p=0.041)$, and endotracheal aspirate (ETA) $P$. aeruginosa concentration $(p=0.024)$. A model comprising ETA bacterial burden, IL-10, and TNF-a yielded moderate discrimination for the diagnosis of VAP (area of the receiver operating curve $0.82,95 \% \mathrm{Cl} 0.61-1.00$ ).

(Continued on next page)
\end{abstract}


(Continued from previous page)

Conclusions: Our findings demonstrate anti-inflammatory effects associated with the Trendelenburg position. In this reliable model of VAP, ETA culture showed good diagnostic accuracy, whereas systemic IL-10 and TNF-a marginally improved accuracy. Further clinical studies will be necessary to confirm clinical value of the Trendelenburg position as a measure to hinder inflammation during mechanical ventilation and significance of systemic IL-10 and TNF- $a$ in the diagnosis of VAP.

Keywords: Trendelenburg, Semirecumbent, Inflammation, Interleukin, Mechanical ventilation, Ventilator-associated pneumonia

\section{Background}

Ventilator-associated pneumonia (VAP) is a common iatrogenic pulmonary complication in critically ill patients on mechanical ventilation (MV) [1-3]. Clinical presentation of VAP is highly heterogenous ranging from mild to highly severe [4], potentially causing a systemic cytokine storm and septic shock [5]. Many efforts have been made to fully characterize pathophysiology of the disease and the host inflammatory response, improve diagnostic accuracy, and develop efficacious preventive strategies $[2,3]$.

Among the available preventive interventions [6], body position plays a critical role. Currently, intensive care unit (ICU) patients are kept with the head of the bed oriented above $30^{\circ}$ to avoid gastro-pulmonary aspiration, namely the semirecumbent position [7]. A recent clinical trial has also tested preventive efficacy of the Trendelenburg position, which limits gravity-driven aspiration of oropharyngeal secretions [8]. Nevertheless, to date, the effects of body position on the host inflammatory response and potential association with the development of VAP are still unknown.

Inflammatory biomarkers in blood or bronchoalveolar lavage fluids of patients with VAP [9-11] not only have been tested to characterize inflammation but also to accurately and promptly diagnose VAP. Indeed, VAP is currently diagnosed using clinical criteria and microbiology cultures, which yield low specificity/sensitivity and are often too slow for clinical needs [12]. Unfortunately, aforementioned clinical studies were biased by the well-recognized challenges in VAP diagnosis, the extreme heterogeneity among ICU populations and degrees of severity. As a result, VAP still lacks a clinical diagnostic gold-standard.

We previously developed a reliable animal model of VAP [13] to circumvent some of aforementioned limitations encountered in clinical settings and to specifically evaluate novel diagnostic and preventive strategies. This model was recently used to study efficacy of (1) inverse-ratio ventilation with positive end-expiratory pressure (PEEP) or (2) the Trendelenburg position in the prevention of VAP. These ventilatory settings were applied because mucus clearance is enhanced through inverse-ratio ventilation $[14,15]$ and the Trendelenburg position [16], while gravity-driven pulmonary aspiration is reduced through PEEP [17].

\section{Methods}

\section{Aim, design, and settings}

We performed a secondary analysis of a previous study [18], conducted at the Division of Animal Experimentation, University of Barcelona, Barcelona, Spain. The primary goals of this secondary analysis were to evaluate dynamics of inflammatory biomarkers during application of novel VAP preventive strategies and to ascertain significance of various clinical parameters and cytokines in the diagnosis of VAP. Animals were managed according 
to the local guidelines and regulations for the use and care of animals. The animal experimentation ethical committee reviewed and approved the study protocol. Additional details on animal handling and methods are reported in previous publications $[13,18]$.

\section{Animal preparation and handling}

We studied 21 Large White-Landrace female pigs, orotracheally intubated and mechanically ventilated. Animals were anesthetized and paralyzed. Endogenous pneumonia was prevented with ceftriaxone. The femoral artery and jugular vein were cannulated for hemodynamic monitoring and blood sampling.

\section{Clinical parameters}

Body temperature, white blood cell count, and arterial partial pressure of oxygen were assessed before bacterial challenge and at 24,48 , and $72 \mathrm{~h}$ thereafter. The arterial partial pressure of oxygen per inspiratory fraction of oxygen ratio $\left(\mathrm{PaO}_{2} / \mathrm{F}_{\mathrm{I}} \mathrm{O}_{2}\right)$ was computed. At the same time points, serum creatinine and alanine transaminase were measured. Of note, reference values of aforementioned parameters in pigs are similar to those in humans. Finally, at $72 \mathrm{~h}$, we collected tracheal secretions for quantitative microbiology culture, we qualitatively evaluated purulence, and we computed the clinical pulmonary infection score (CPIS), as described in Table 1.

\section{Randomization}

Following surgical preparation, pigs were randomized as follows:

1. Control: Pigs were placed in prone position and ventilated as reported above, but without PEEP. As previously reported [17, 19], the surgical bed was oriented approximately $30^{\circ}$ in the anti-Trendelenburg position to achieve an orientation of the respiratory system as in the semirecumbent position in humans.

2. Expiratory flow bias and PEEP (EFB + PEEP): Pigs were positioned as in the control group. The duty cycle $\left(\mathrm{T}_{\mathrm{I}} / \mathrm{T}_{\mathrm{TOT}}\right)$ was adjusted daily to achieve a mean expiratory-inspiratory flow bias of $10 \mathrm{~L} / \mathrm{min}$ and PEEP was set at $5 \mathrm{~cm} \mathrm{H}_{2} \mathrm{O}$. As previously described [17], this ventilatory strategy was aimed at improving mucus clearance through the resulting expiratory flow bias [14], and hindering pulmonary aspiration of colonized subglottic secretions through PEEP.

Table 1 Clinical pulmonary infection score

\begin{tabular}{llll}
\hline CPIS points & 0 & 1 & 2 \\
\hline Tracheal secretions & Rare & Abundant & Abundant and purulent \\
Chest radiograph infiltrates & No infiltrate & Disseminated & Localized \\
Temperature $\left({ }^{\circ} \mathrm{C}\right)$ & $\geq 36.5$ and $\leq 38.4$ & $\geq 38.5$ and $\leq 38.9$ & $\geq 39$ and $\leq 36$ \\
Leukocytes count $\left(10^{3} / \mu \mathrm{l}\right)$ & $\geq 4$ and $\leq 11$ & $<4$ or $>11$ & \\
$\mathrm{~Pa}_{\mathrm{O} 2} / \mathrm{F}_{\mathrm{IO2}}(\mathrm{mmHg})$ & $\geq 240$ & & $\leq 240$ \\
Microbiology & Negative & & Positive \\
\hline
\end{tabular}

CPIS clinical pulmonary infection score. A CPIS score value $\geq 6$ was considered suggestive of pneumonia. Chest radiographs were not collected. Nevertheless, given the initial healthy status of the animal and the macroscopic lung examination upon autopsy, we assumed in all pigs localized chest radiograph infiltrates in case of confirmed pulmonary infiltrates upon autopsy 
3. Trendelenburg: Pigs were in prone position and ventilated as in the control group. The surgical bed was oriented $5^{\circ}$ below horizontal

To achieve aforementioned ventilatory endpoints, airway pressure was measured proximally to the endotracheal tube with a pressure transducer (MPX 2010 DP; Motorola, Phoenix, AZ, USA). Respiratory flow rates were measured with a heated pneumotachograph (Fleisch no. 2; Fleisch, Lausanne, Switzerland). Flow and pressure signals were recorded on a personal computer and assessed with dedicated software (Colligo; Elekton, Milan, Italy).

\section{Bacterial challenge}

Shortly after randomization, $5 \mathrm{~mL}$ of $10^{7}-10^{8}$ ceftriaxone-resistant Pseudomonas aeruginosa suspension was instilled into the oropharynx to colonize the oropharynx and promote aspiration of $P$. aeruginosa-laden oropharyngeal secretions and VAP [13].

\section{Systemic biomarkers}

Prior to bacterial challenge, and at 24,48 , and $72 \mathrm{~h}$ thereafter, blood was drawn for measurement of serum inflammatory markers. Blood was centrifuged at $3000 \mathrm{rpm}$ at $4{ }^{\circ} \mathrm{C}$ for $15 \mathrm{~min}$, and serum aliquots were stored at $-80{ }^{\circ} \mathrm{C}$. Serum interferon (INF)- $\gamma$; interleukin (IL)-1 $\alpha$; IL-1 $\beta$; IL-1 receptor antagonist (RA); IL-2; IL-4; IL-6; IL-8; IL-10; IL-12; IL-18; and tumor necrosis factor (TNF)- $\alpha$ were quantified by bead-based multiplex assays with Luminex $\mathrm{xMAP}^{\oplus}$ technology (Millipore Iberica, S.A., Madrid, Spain). Whereas tissue factor, angiotensin-2, adrenomedullin, and protein C-reactive protein were quantified through enzyme-linked immunosorbent assay (ELISA) (Bionova cientifica S.L., Madrid, Spain). Accuracy in cytokine quantification by Luminex $\mathrm{xMAP}^{\circ}$ technology is comparable to the ELISA assay [20-22]. Nevertheless, Luminex $\mathrm{xMAP}^{\circledR}$ assay allows measurement of multiple cytokines simultaneously providing additional benefits. All inflammatory markers data are reported as $\log \mathrm{pg} / \mathrm{L}$. Aforementioned biomarkers were chosen based on previous clinical studies assessing systemic and pulmonary inflammation during pneumonia [10, 11, 23-27].

\section{Autopsy, microbiological, histological studies, and VAP definitions}

Tracheal secretions were collected before autopsy and $P$. aeruginosa concentration score was computed as follows: $0:<3.0 \log 10 \mathrm{cfu} / \mathrm{mL} ; 1: 3.0-3.9 ; 2: 4.0-4.9 ; 3: 5-6 ; 4$ : $>6 \log \mathrm{cfu} / \mathrm{mL}$. Seventy-six hours after tracheal intubation, the animal was euthanized. We took two samples from the most affected region of each of the five lobes for microbiological assessments. Pulmonary infections were clinically suspected when two of the following clinical signs were present: white blood cell (WBC) $\geq 14,000$ per $\mathrm{mm}^{3}$, purulent secretion, and body temperature $\geq 38.5{ }^{\circ} \mathrm{C}$. Pulmonary biopsies were evaluated by pathologists and microbiologists blinded to the study treatments, and VAP was confirmed according to a lobar histological injury score $\geq 3$ (3 points = pneumonia, 4 points $=$ confluent pneumonia, and 5 points $=$ abscessed pneumonia), associated with a quantitative $P$. aeruginosa culture $\geq 3 \log \mathrm{cfu} / \mathrm{g}[19,28,29]$.

\section{Statistical analysis}

A sample size of at least seven animals per group was calculated on the basis of the primary outcome of the original study [18], which was powered to detect a difference in 
P. aeruginosa lung tissue concentration between control, EFB + PEEP, and Trendelenburg groups of $3 \pm 1.5 \log \mathrm{cfu} / \mathrm{g}, 1 \pm 1.5 \log \mathrm{cfu} / \mathrm{g}$, and $0 \pm 1.5 \log \mathrm{cfu} / \mathrm{g}$, respectively, for an assumed effect size of 0.83 , a fixed power of $0.85 \%$, and an alpha error probability of 0.05. Restricted maximum likelihood (REML) analysis, based on repeated measures approach, including type of infection, study treatments, and study times, were conducted to evaluate differences in cytokines concentrations. Post-hoc multiple comparisons among groups were computed through Bonferroni adjustment. The area under the receiver operating curves (ROC-AUC) of clinical parameters were computed. Relationship between inflammatory biomarkers and $P$. aeruginosa lung tissue concentration was evaluated by linear regression analysis. Statistical analyses were performed using SAS software (version 9.4; SAS Institute, Cary, NC).

\section{Results}

Inflammatory biomarkers of six, eight, and seven pigs-originally randomized in the control, EFB + PEEP, and Trendelenburg groups, respectively-were available for analysis. One pig in the EFB + PEEP group was euthanized earlier for accidental extubation and colonization/histology of the lungs was not examined. Thus, we ultimately analyzed data of six control pigs and seven animals in the EFB + PEEP and Trendelenburg groups. Overall, ten animals developed VAP (four controls, six EFB + PEEP, and zero Trendelenburg). In the control, EFB + PEEP, and Trendelenburg groups, lung P. aeruginosa burden was $2.4 \pm 1.5,1.9 \pm 2.1$, and $0.3 \pm 0.6 \log _{10} \mathrm{cfu} / \mathrm{mL}$, respectively $(p=0.020)$. Whereas, lung bacterial burden was $2.4 \pm 1.9 \log _{10} \mathrm{cfu} / \mathrm{g}$ in animals with VAP, in comparison with $0.6 \pm 0.9$ in animals without VAP $(p<0.001)$.

\section{Clinical and microbiology studies}

Table 2 reports clinical and microbiology variables among study groups, whereas Table 3 report difference between animals with or without VAP. Among study treatments, the

Table 2 Clinical and microbiology variables among study treatments

\begin{tabular}{|c|c|c|c|c|c|}
\hline Parameter & $\begin{array}{l}\text { Time of } \\
\text { assessment }\end{array}$ & Control (6) & $\mathrm{EFB}+\mathrm{PEEP}(7)$ & Trendelenburg (7) & $p$ value \\
\hline \multirow[t]{2}{*}{ Body temperature $\left({ }^{\circ} \mathrm{C}\right)$} & $\begin{array}{l}\text { Throughout study } \\
\text { time }\end{array}$ & $37.0 \pm 1.6$ & $38.4 \pm 2.1$ & $37.1 \pm 1.3$ & \multirow[t]{2}{*}{$<0.001$} \\
\hline & $72 \mathrm{~h}$ & $37.5 \pm 0.9$ & $39.6 \pm 0.8$ & $36.7 \pm 1.3$ & \\
\hline \multirow[t]{2}{*}{ White blood cells $\left(\times 10^{9} / L\right)$} & $\begin{array}{l}\text { Throughout study } \\
\text { time }\end{array}$ & $17.2 \pm 6.8$ & $13.4 \pm 4.3$ & $17.7 \pm 5.9$ & \multirow[t]{2}{*}{0.133} \\
\hline & $72 \mathrm{~h}$ & $17.3 \pm 7.5$ & $12.7 \pm 6.1$ & $18.1 \pm 2.8$ & \\
\hline \multirow[t]{2}{*}{$\mathrm{PaO}_{2} / \mathrm{FlO}_{2}(\mathrm{mmHg})$} & $\begin{array}{l}\text { Throughout study } \\
\text { time }\end{array}$ & $\begin{array}{l}424.8 \pm \\
88.9\end{array}$ & $423.3 \pm 76.5$ & $443.6 \pm 43.3$ & \multirow[t]{2}{*}{0.312} \\
\hline & $72 \mathrm{~h}$ & $\begin{array}{l}378.0 \pm \\
85.0\end{array}$ & $339.1 \pm 26.5$ & $437.0 \pm 40.6$ & \\
\hline CPIS & $72 \mathrm{~h}$ & $4.6 \pm 0.9$ & $6.3 \pm 0.5$ & $4.6 \pm 0.9$ & 0.035 \\
\hline $\begin{array}{l}\text { Tracheal aspirate } P \text {. aeruginosa } \\
\text { quantitative culture }\left(\log _{10} \mathrm{cfu} / \mathrm{mL}\right)\end{array}$ & $72 \mathrm{~h}$ & $5.9 \pm 1.1$ & $6.0 \pm 0.9$ & $5.6 \pm 1.0$ & 0.487 \\
\hline
\end{tabular}

Data are reported as mean \pm standard deviation of various assessments throughout the study time or only at $72 \mathrm{~h}$. Per each group, number of studied animals are reported between parenthesis. Of note, we report analyses $p$ values of only the values of CPIS and tracheal aspirate $P$. aeruginos $a$ quantitative culture at $72 \mathrm{~h}$, whereas for the remaining parameters, we report $p$ values of analysis of all assessed parameters throughout the study time $(0,24,48$, and $72 \mathrm{~h})$. CPIS was computed as reported in the Table 1. $\mathrm{PaO}_{2} / \mathrm{FIO}_{2}$ arterial partial pressure of oxygen/inspiratory fraction of oxygen ratio, CPIS clinical pulmonary infection score, $E F B+P E E P$ expiratory flow bias and positive end expiratory pressure group 
Table 3 Clinical and microbiology variables between animals with or without VAP

\begin{tabular}{lllll}
\hline Parameter & Time of assessment & No-VAP $(10)$ & VAP $(10)$ & $p$ value \\
\hline Body temperature $\left({ }^{\circ} \mathrm{C}\right)$ & Throughout study time & $37.2 \pm 1.6$ & $37.9 \pm 1.9$ & 0.592 \\
& $72 \mathrm{~h}$ & $37.2 \pm 1.6$ & $38.8 \pm 1.1$ & \\
White blood cells $\left(\times 10^{9} / \mathrm{L}\right)$ & Throughout study time & $16.8 \pm 5.6$ & $15.3 \pm 6.4$ & 0.420 \\
& $72 \mathrm{~h}$ & $16.5 \pm 4.1$ & $15.2 \pm 7.5$ & \\
$\mathrm{PaO}_{2} / \mathrm{FIO}_{2}(\mathrm{mmHg})$ & Throughout study time & $438.5 \pm 58.5$ & $390.5 \pm 40.1$ & 0.946 \\
& $72 \mathrm{~h}$ & $430.4 \pm 40.5$ & $334.7 \pm 47.7$ & \\
$\mathrm{CPIS}$ & $72 \mathrm{~h}$ & $4.6 \pm 0.9$ & $5.8 \pm 0.9$ & 0.260 \\
Tracheal aspirate $P$. aeruginosa & $72 \mathrm{~h}$ & $5.4 \pm 1.0$ & $6.3 \pm 0.7$ & 0.041 \\
quantitative culture $\left(\log _{10} \mathrm{cfu} / \mathrm{mL}\right)$ & & & & \\
\hline
\end{tabular}

Data are reported as mean \pm standard deviation of various assessments throughout the study time or only at $72 \mathrm{~h}$. Per each group, number of studied animals are reported between parenthesis. Of note, we report analyses $p$ values of only the values of CPIS and tracheal aspirate $P$. aeruginosa quantitative culture at $72 \mathrm{~h}$, whereas for the remaining parameters, we report $p$ values of analysis of all assessed parameters throughout the study time $(0,24,48$, and $72 \mathrm{~h})$. CPIS was computed as reported in the Table 1. VAP ventilator-associated pneumonia, $\mathrm{PaO}_{2} / \mathrm{FIO}_{2}$ arterial partial pressure of oxygen/inspiratory fraction of oxygen ratio, CPIS clinical pulmonary infection score

following variables changed significantly: body temperature $(37.0 \pm 1.6,38.4 \pm 2.1$, and $37.1 \pm 1.3{ }^{\circ} \mathrm{C}$ in the control, EFB + PEEP, and Trendelenburg groups, respectively, $p<0.001$ ) and CPIS calculated at $72 \mathrm{~h}$, before autopsy $(4.6 \pm 0.9,6.3 \pm 0.5$, and $4.6 \pm 0.9, p=0.035)$. Whereas, in animals with VAP, $P$. aeruginosa concentration in tracheal aspirates was $6.3 \pm 0.6 \log _{10} \mathrm{cfu} / \mathrm{mL}$, in comparison with $5.4 \pm 0.9$ in animals without VAP $(p=0.024)$. As for others clinical parameters of organ injury, creatinine (pig reference value $06-1.2 \mathrm{mg} / \mathrm{dL})$ was $1.16 \pm 0.38,1.42 \pm 0.45$, and $1.40 \pm 0.28 \mathrm{mg} / \mathrm{dL}$ in the control, EFB + PEEP, and Trendelenburg groups, respectively, $(p<0.001)$; whereas in the animals with VAP was $1.41 \pm 0.45$ and $1.24 \pm 0.31$ without VAP was $(p<0.001)$. Finally, alanine aminotransferase (pig reference value 10-40 UI/L) was $41.7 \pm 16.4,34.4 \pm 13.9$, and $25.8 \pm 9.6 \mathrm{U} / \mathrm{L}$ in the control, EFB + PEEP, and Trendelenburg groups, respectively, $(p<0.001)$; whereas in the animals with VAP was $31.2 \pm 13.8$ and $37.3 \pm 16.2 \mathrm{U} / \mathrm{L}$ without VAP $(p=0.914)$.

\section{The effects of study treatments on serum inflammatory markers}

As depicted in Table 4, study treatments changed significantly levels of INF- $\gamma(p=0.047)$, IL-1 $\beta(p=0.021)$, IL-1RA $(p<0.001)$, IL-4 $(p=0.005)$, IL-8 $(p=0.008)$, IL-18 $(p=0.050)$, and angiotensin-2 $(p=0.048)$. In particular, as depicted in Fig. 1 , at the end of the study, animals positioned in Trendelenburg presented lower levels of all aforementioned inflammatory markers, but INF- $\gamma$ and angiotensin-2.

\section{Serum inflammatory markers to diagnose ventilator-associated pneumonia}

As depicted in Table 5, there were significant differences in the concentrations of IL-10 $(p=0.035)$ and TNF- $\alpha(p=0.041)$ when comparing animals with or without VAP. We report in Fig. 2 dynamics of aforementioned cytokines, among animals with or without VAP.

On the basis of aforementioned findings, the capacity for IL-10 and TNF- $\alpha$ and tracheal secretions $P$. aeruginosa burden to diagnose VAP were tested, and ROC curves computed (Table 6 and Fig. 3). We found that the best model, which provided moderate discrimination for the diagnosis of VAP, with a ROC-AUC of 0.82 (95\% CI 0.611.00) comprised all aforementioned parameters. Linear regression analyses showed that IL-10 ( $p=0.995)$, TNF- $\alpha(p=0.160)$, and tracheal secretions $P$. aeruginosa burden score 
Table $\mathbf{4}$ Inflammatory markers among study groups

\begin{tabular}{lllll}
\hline Inflammatory marker $\left(\log _{10} \mathrm{pg} / \mathrm{L}\right)$ & Control $(6)$ & EFB + PEEP $(7)$ & Trendelenburg $(7)$ & $p$ value \\
\hline INF- & $1.70 \pm 0.42$ & $1.44 \pm 0.33$ & $1.76 \pm 0.59$ & 0.048 \\
IL-1a & $-0.62 \pm 0.47$ & $-0.98 \pm 0.54$ & $-0.80 \pm 0.64$ & 0.709 \\
IL-1 $\beta$ & $0.35 \pm 0.41$ & $-0.06 \pm 0.49$ & $-0.03 \pm 0.72$ & 0.021 \\
IL-1RA & $1.33 \pm 0.33$ & $1.28 \pm 0.31$ & $0.82 \pm 0.33$ & $<0.001$ \\
IL-2 & $-0.04 \pm 0.37$ & $-0.29 \pm 0.51$ & $-0.25 \pm 0.79$ & 0.558 \\
IL-4 & $1.01 \pm 0.52$ & $0.25 \pm 0.73$ & $0.38 \pm 0.83$ & 0.005 \\
IL-6 & $-0.01 \pm 0.29$ & $-0.07 \pm 0.42$ & $-0.15 \pm 0.63$ & 0.806 \\
IL-8 & $0.16 \pm 0.45$ & $-0.03 \pm 0.42$ & $-0.08 \pm 0.41$ & 0.008 \\
IL-10 & $-0.42 \pm 0.45$ & $0.13 \pm 0.41$ & $0.21 \pm 0.53$ & 0.450 \\
IL-12 & $0.93 \pm 0.13$ & $0.77 \pm 0.18$ & $0.74 \pm 0.23$ & 0.058 \\
IL-18 & $1.19 \pm 0.31$ & $0.94 \pm 0.31$ & $0.96 \pm 0.40$ & 0.050 \\
TNF-alpha & $-0.16 \pm 0.53$ & $-0.08 \pm 0.48$ & $-0.31 \pm 0.49$ & 0.814 \\
TF & $1.95 \pm 0.20$ & $1.98 \pm 0.16$ & $2.04 \pm 0.17$ & 0.232 \\
Angiotensin-2 & $1.73 \pm 0.21$ & $1.87 \pm 0.17$ & $1.62 \pm 0.23$ & 0.048 \\
ADM & $2.79 \pm 0.80$ & $2.99 \pm 0.24$ & $2.84 \pm 0.65$ & 0.515 \\
CRP & $4.15 \pm 0.39$ & $3.86 \pm 0.55$ & $3.55 \pm 0.51$ & 0.052 \\
\hline Def & &
\end{tabular}

Determinations of interferon- $\gamma$ (INF- $\gamma$ ), interleukin (IL)-1a, IL-1 $\beta$, IL-1 receptor antagonist (RA), IL-2, IL-4, IL-6, IL-6, IL-8, IL-10, IL12, IL-18, tumor necrosis factor (TNF)-a, tissue factor (TF), angiotensin-2, adrenomedullin (ADM), and C-reactive protein (CRP) in serum throughout the study are shown among study groups and in animals with or without VAP. Data are reported as mean \pm standard deviation based on $\log _{10}$ transformation. EFB + PEEP expiratory flow bias and positive end expiratory pressure group

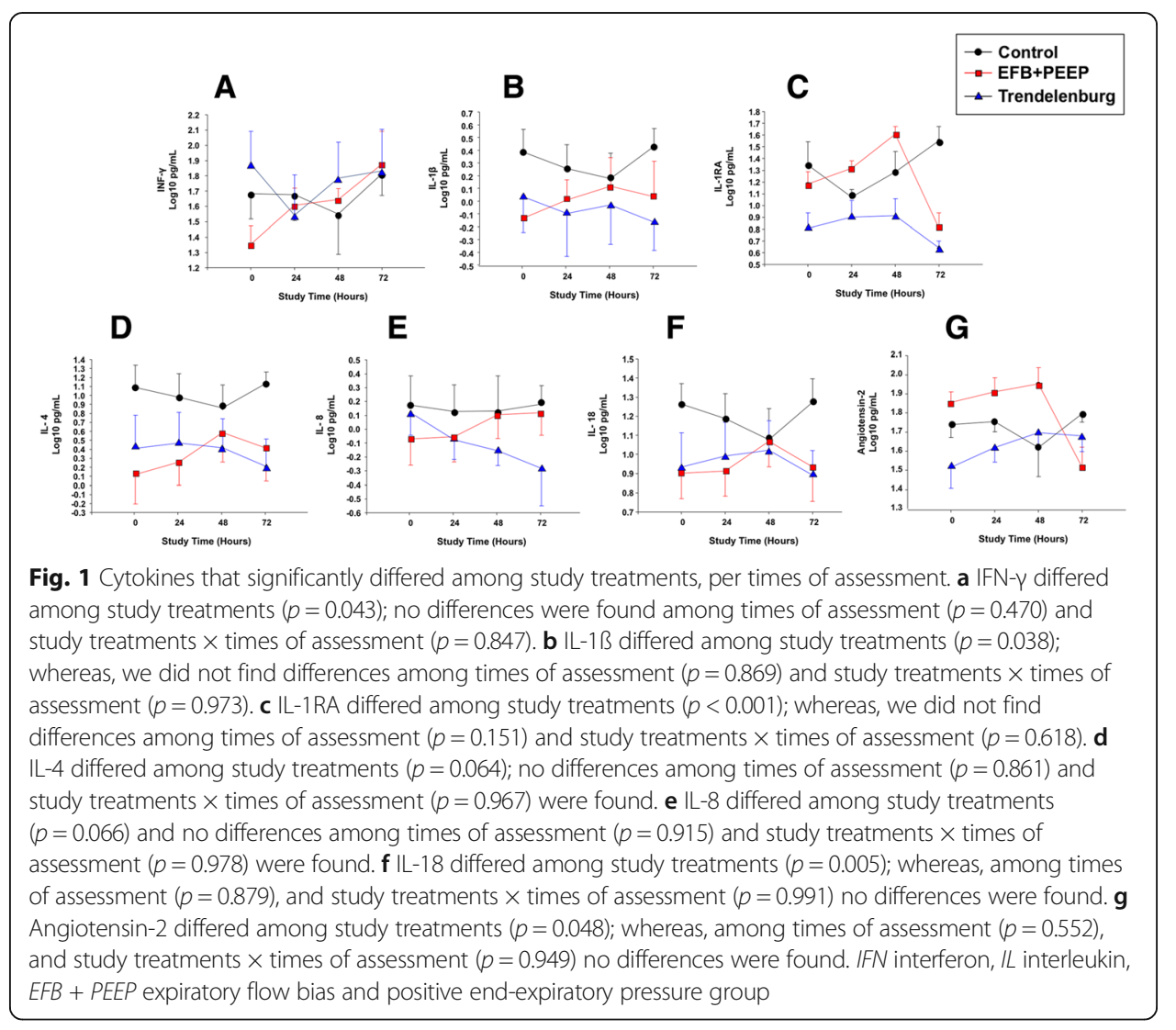


Table $\mathbf{5}$ Inflammatory markers between animals with or without VAP

\begin{tabular}{|c|c|c|c|}
\hline Inflammatory marker ( $\left.\log _{10} \mathrm{pg} / \mathrm{L}\right)$ & No-VAP (10) & $\operatorname{VAP}(10)$ & $p$ value \\
\hline INF-Y & $1.66 \pm 0.58$ & $1.60 \pm 0.35$ & 0.165 \\
\hline IL-1a & $-0.84 \pm 0.58$ & $-0.79 \pm 0.57$ & 0.339 \\
\hline IL-1 $\beta$ & $0.04 \pm 0.67$ & $-0.12 \pm 0.48$ & 0.640 \\
\hline IL-1RA & $0.99 \pm 0.42$ & $1.28 \pm 0.31$ & 0.663 \\
\hline IL-2 & $-0.30 \pm 0.69$ & $-0.10 \pm 0.47$ & 0.152 \\
\hline IL-4 & $-0.58 \pm 0.80$ & $-0.49 \pm 0.75$ & 0.130 \\
\hline IL-6 & $-0.14 \pm 0.53$ & $-0.01 \pm 0.40$ & 0.283 \\
\hline IL-8 & $0.05 \pm 0.51$ & $-0.01 \pm 0.35$ & 0.329 \\
\hline IL-10 & $0.15 \pm 0.47$ & $0.36 \pm 0.48$ & 0.035 \\
\hline IL-12 & $0.77 \pm 0.20$ & $0.86 \pm 0.19$ & 0.281 \\
\hline IL-18 & $1.03 \pm 0.40$ & $1.03 \pm 0.31$ & 0.707 \\
\hline TNF-alpha & $-0.33 \pm 0.47$ & $-0.04 \pm 0.50$ & 0.041 \\
\hline TF & $2.01 \pm 0.15$ & $1.98 \pm 0.21$ & 0.517 \\
\hline Angiotensin-2 & $1.67 \pm 0.21$ & $1.81 \pm 0.22$ & 0.969 \\
\hline ADM & $2.78 \pm 0.71$ & $2.99 \pm 0.40$ & 0.175 \\
\hline CRP & $3.69 \pm 0.46$ & $4.04 \pm 0.57$ & 0.189 \\
\hline
\end{tabular}

Determinations of interferon- $\gamma$ (INF- $\gamma$ ), interleukin (IL)-1 a, IL-1ß, IL-1 receptor antagonist (RA), IL-2, IL-4, IL-6, LL-6, IL-8, IL-10, $\mathrm{IL}-12$, IL-18, tumor necrosis factor (TNF)- $a$, tissue factor (TF), angiotensin-2, adrenomedullin (ADM), and C-reactive protein (CRP) in serum throughout the study are shown among study groups and in animals with or without VAP. Data are reported as mean \pm standard deviation based on $\log _{10}$ transformation. VAP ventilator-associated pneumonia

$(p=0.068)$ were not significantly associated with lung P. aeruginosa burden. In Fig. 4, we depicts tracheal secretions $P$. aeruginosa burden capability to predict lung burden, clustered by study groups and development of VAP. Of note, in animals that developed VAP, tracheal secretions $P$. aeruginosa burden was poorly associated with lung burden $(p=0.131)$.

\section{Discussion}

In this study, we observed that in pigs, challenged into the oropharynx with $P$. aeruginosa, the lateral-Trendelenburg position reduced systemic inflammation through the

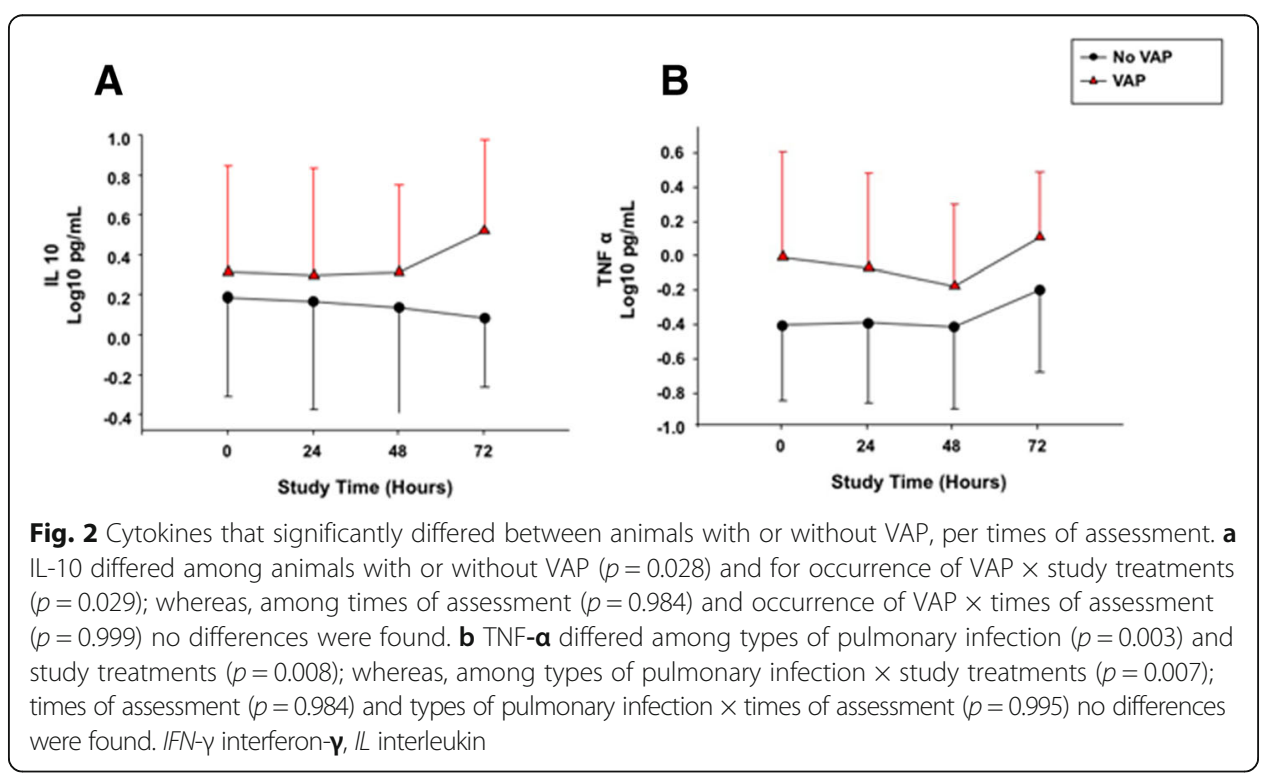


Table 6 Receiver operating curves parameters

\begin{tabular}{|c|c|c|c|c|c|c|}
\hline & AU-ROC $(95 \% \mathrm{Cl})$ & $\begin{array}{l}\text { Best cut-off } \\
\text { value }^{*}\end{array}$ & Sensitivity & Specificity & PPV & NPV \\
\hline \multicolumn{7}{|l|}{ Single VAP diagnostic parameter } \\
\hline IL-10 (log $\left.\log _{10} \mathrm{pg} / \mathrm{L}\right)$ & $0.71(0.47-0.96)$ & 0.250 & $80 \%$ & $70 \%$ & $73 \%$ & $78 \%$ \\
\hline TNF-a $\left(\log _{10} \mathrm{pg} / \mathrm{L}\right)$ & $0.69(0.44-0.96)$ & -0.190 & $89 \%$ & $56 \%$ & $67 \%$ & $83 \%$ \\
\hline $\begin{array}{l}\text { Tracheal secretion } P \text {. aeruginosa } \\
\text { concentration (cfu/mL) }\end{array}$ & $0.80(0.58-1.00)$ & 6.34 & $70 \%$ & $90 \%$ & $88 \%$ & $75 \%$ \\
\hline $\begin{array}{l}\text { Tracheal secretion } P \text {. aeruginosa } \\
\text { concentration score }\end{array}$ & $0.71(0.50-0.92)$ & 4 & $80 \%$ & $60 \%$ & $67 \%$ & $75 \%$ \\
\hline \multicolumn{7}{|l|}{ Combined VAP diagnostic parameter $^{\mathrm{b}}$} \\
\hline $\begin{array}{l}\text { IL-10 + tracheal secretion P. aeruginosa } \\
\text { concentration score }\end{array}$ & $0.78(0.58-0.99)$ & 5 & $70 \%$ & $80 \%$ & $78 \%$ & $78 \%$ \\
\hline $\begin{array}{l}\text { TNF- } a+\text { tracheal secretion } P \text {. aeruginosa } \\
\text { concentration score }^{a}\end{array}$ & $0.73(0.51-0.95)$ & 5 & $78 \%$ & $67 \%$ & $70 \%$ & $75 \%$ \\
\hline $\begin{array}{l}\text { IL-10 + TNF-a + tracheal secretion } \\
\text { P. aeruginosa concentration score }\end{array}$ & $0.82(0.61-1.00)$ & 6 & $67 \%$ & $89 \%$ & $86 \%$ & $73 \%$ \\
\hline
\end{tabular}

* Receiver operating curves of ventilator-associated pneumonia diagnostic parameters and their combination. *The optimal cut-off values were computed through the Youden's index $(\mathrm{J})$, which is the maximal vertical distance between the ROC curve and the first bisector (or chance line)

${ }^{a}$ The tracheal secretion $P$. aeruginosa concentration score was computed as follows: $0:<3.0 \log \mathrm{cfu} / \mathrm{mL} ; 1: 3.0-3.9 \log \mathrm{cfu} / \mathrm{mL}$; 2: 4.0-5.9 log cfu/mL; 3: 5-6 log cfu/mL; 4: > $6 \log \mathrm{cfu} / \mathrm{mL}$. AU-ROC area under receiver operating curve, $\mathrm{Cl}$ confidence interval, $P P V$ positive predictive value, NPV negative predictive value, $I L$ interleukin, TNF tumor necrosis factor

${ }^{\mathrm{b}}$ To combine interleukins and tracheal secretion $P$. aeruginosa concentration score, we categorized IL-10 and TNF- $\mathrm{a}$ as $0-1$ values, based on the best cut-off value

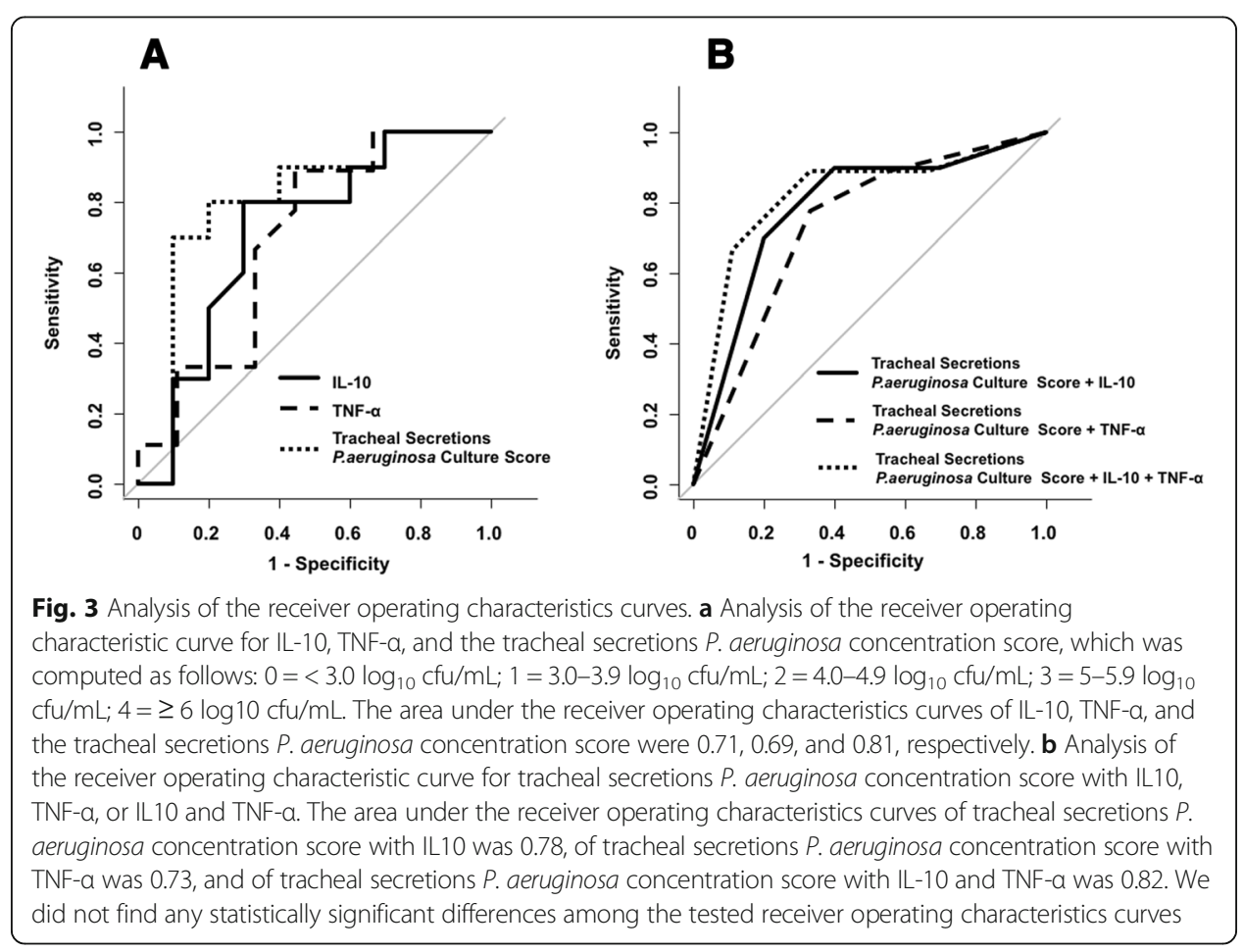


prevention of VAP. Also, this study demonstrated that in a validated animal model of VAP, serum IL-10 and TNF- $\alpha$ were the only cytokines that varied during VAP development. Yet, culture of tracheal secretions still outperformed all evaluated diagnostic parameters.

\section{Effects of study interventions on systemic inflammation}

We consistently demonstrated in previous studies in sheep [16, 30] and pigs [17, 31] that the Trendelenburg position avoided VAP, but to the best of our knowledge, this is the first comprehensive report regarding its effects on systemic inflammation. Our study adds to previous literature and suggests that during mechanical ventilation, the Trendelenburg position might limit systemic inflammation. In particular, we found that IL-1 $\beta$, IL-1RA, IL-4, and IL-8 were consistently lower in the Trendelenburg group. In contrast, modifying duty cycle and PEEP did not have any effect on systemic inflammation and, as previously reported [18], on VAP. Importantly, our study primarily focused on cytokines that might variate during the development of VAP, thus it is plausible that the association of aforementioned cytokines with the Trendelenburg position might have been related to the prevention of VAP. Indeed, previous findings confirmed higher levels of IL-1 $\beta$, specifically in bronchoalveolar lavage fluids $[24,26]$, of patients with VAP, whereas an association between systemic and pulmonary IL-1RA and VAP [10, 26] has not been established. As for IL-4, this biomarker has not been tested in VAP and preliminary studies have found in IL-4-knockout mice resistance to $P$. aeruginosa pulmonary infection and increased TNF- $\alpha$ production [32]. Also in pediatric patients with pneumonia, IL-4 was a reliable marker of severity of the disease [23]. Finally, clinical studies have confirmed a surge in IL-8 with VAP [27].

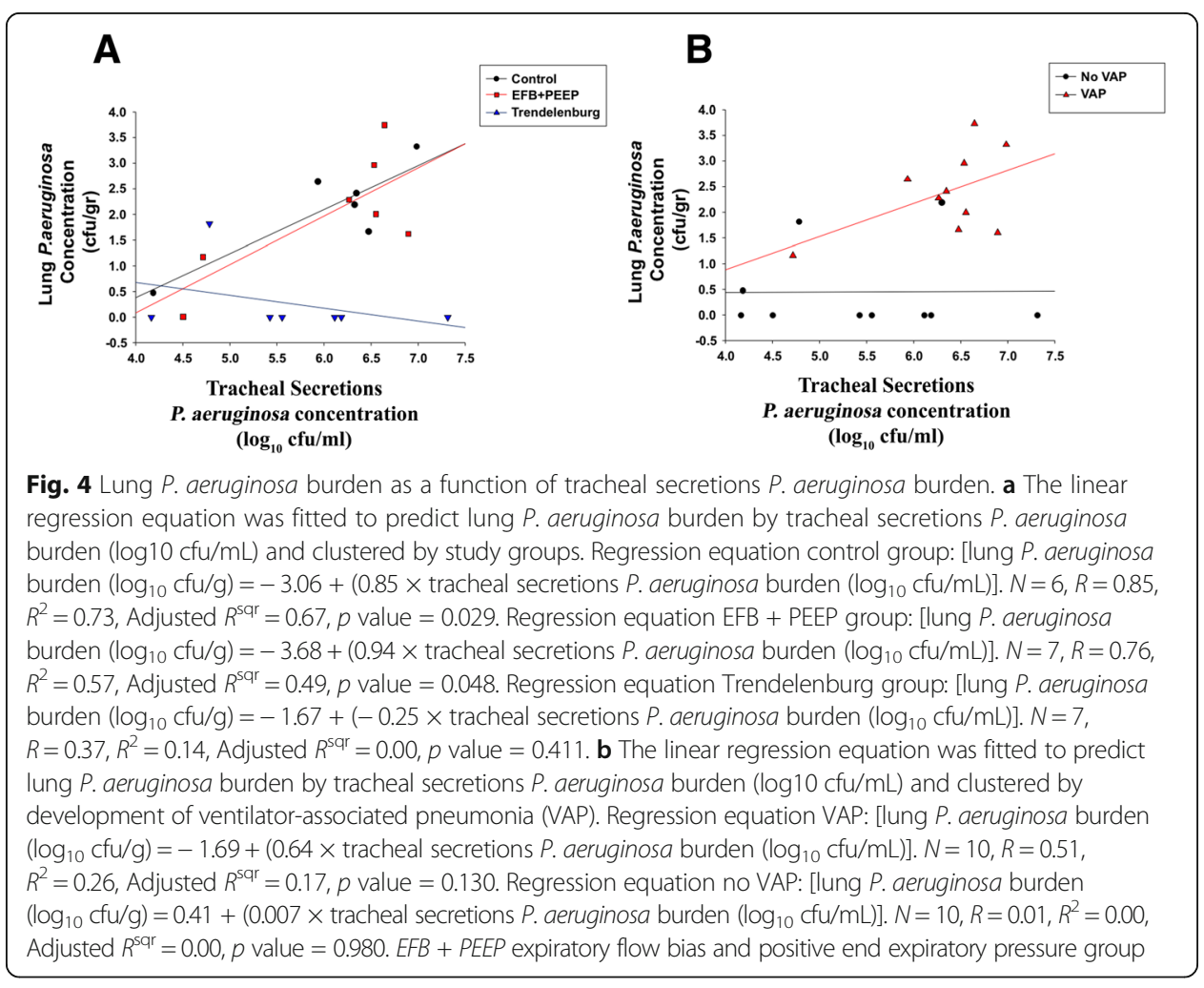




\section{VAP diagnosis}

Considering that in clinical settings VAP still lacks of a diagnostic gold standard, an additional purpose of our study was assessing accuracy of several diagnostic parameters. In line with previous reports [29], clinical variables, such as body temperature, WBC, and $\mathrm{PaO}_{2} / \mathrm{FIO}_{2}$, were highly unspecific. As for systemic cytokines, previous clinical studies [10, 24, 25, 33-36] have appraised biomarkers in bloodstream, lungs, and pleural space to find the best diagnostic marker. Yet, discriminatory inflammatory markers that could reliably diagnose VAP are difficult to be identified in clinical settings, because at the time of VAP development, ICU patients often present other infections. Furthermore, ICU patients might be in an immune-paralysis state [37-39], which increases the risk of developing VAP [25], while hindering patient's inflammatory response. Given the abovementioned challenges, the use of a reliable animal model of VAP [28], developed in healthy animals without concomitant illnesses, could facilitate identification of diagnostic markers and redirect on the most promising.

We found that only IL-10 and TNF- $\alpha$ were independently associated with the development of VAP. IL-10 is an anti-inflammatory cytokine that inhibits activation and effector function of T cells, monocytes, and macrophages [40]. Millo and collaborators [26] did not find any variation in plasma and BAL IL-10 in patients who developed VAP. Similarly, Conway Morris et al. confirmed that IL-10 did not have potential value for discriminating VAP from non-infected patients [34]. Whereas, Martin-Loeches and collaborators found significant differences in IL-10 concentration between VAP and no-VAP patients [10]; nevertheless, multivariate analyses failed to corroborate diagnostic value of IL-10. TNF- $\alpha$ is predominately produced by macrophages and exert various effects such as fever, cachexia, and inhibition of tumorigenesis and viral replication. Millo et al. found higher levels of TNF- $\alpha$ in bronchoalveolar lavage fluids of VAP patients [26].

Of note, we found that $P$. aeruginosa endotracheal aspirate (ETA) concentration overcame diagnostic accuracy of all cytokines, yielding an AU-ROC higher than $80 \%$ (Fig. 3). A clinical trial [41] tested diagnostic value of culture of tracheal secretions vs. bronchoalveolar lavage fluids and it did not find any difference between study groups. Thus, latest European [3] and American [2] guidelines for the management of patients with VAP recommended obtaining samples of respiratory secretions to diagnose VAP. Our findings support this recommendation; yet, it is important to emphasize that tracheal secretions culture requires 1 to 3 days before definitive results, ultimately limiting initial therapeutic options. Also, as reported in Fig. 4, we found a marginal association between P. aeruginosa ETA concentration and lung colonization. This could be related to the limited number of animals or to specific features of our model; indeed, following oropharyngeal challenge, the animals consistently developed colonization of the proximal airways, irrespective of the subsequent colonization of the lungs and VAP development.

\section{Clinical implications}

Our preliminary findings should be interpreted in light of the potential clinical applications. First, clinical feasibility of inverse-ratio ventilation is challenging, and given the marginal results reported in our latest analysis and previous studies [18], it should not be recommended in clinical settings. Second, in our studies, we failed to find efficacy of PEEP in reducing systemic inflammation or VAP, but these 
findings are in contrast with a previous clinical study that found lower incidence of VAP in patients ventilated with PEEP of 5 vs. $0 \mathrm{~cm} \mathrm{H}_{2} \mathrm{O}$ [42]. This study was discontinued earlier for low recruitment rate, thus future clinical corroborations are essential to further explore the value of PEEP. Third, the recent results of the Gravity-VAP Trial [8] confirmed preventive benefits associated with the lateral-Trendelenburg position, but the study was discontinued earlier, due to a very low incidence of VAP and marginal effects in secondary outcomes. Of note, in the Gravity-VAP trial, the lateral-Trendelenburg position was applied for only 2 days following intubation, and higher safety was reported in patients who did not present pulmonary infiltrates. Considering the positive results from experimental studies [17, 30,31], but the limitations of the latest randomized trial, risks and benefits of such intervention should be carefully pondered, carefully examining timing and duration of the intervention, which should exclusively be applied to patients who are not intubated for pulmonary causes. Furthermore, pulmonary and systemic inflammation should be monitored. Finally, although our results confirm diagnostic accuracy of ETA, the delay for culture results often causes overtreatment or inappropriate treatment of multi-drug resistant pathogens. Thus, development of novel rapid molecular assays, custom-made for pathogen specific for VAP and for drug resistance genes, are needed. In addition, given the variability in biomarkers concentration among different patient populations and courses of treatment, a comprehensive evaluation of the dynamics of these markers, rather than the absolute cut-off values should be prioritized.

\section{Study limitations}

First, although we conducted a 72-h study, in clinical settings, VAP may develop after several days of MV; therefore, in our model, some pathogenic mechanisms and the inflammatory response could somehow diverge in comparison with the critically ill, ventilated patient. Second, our animals were healthy at the beginning of the study and inflammatory changes were specifically related to the new iatrogenic infection. Nevertheless, in the early phase of the experiment, inflammatory markers could have been affected by the surgical interventions performed during animal preparation. Third, considering the complexity of cytokine signaling pathways in critically ill patients and potential inter-species differences, our results require further validation in humans. Fourth, this was an analysis of animals included in a previous trial [18] and inferences should primary assist for future confirmatory analyses. Fifth, our findings should be discussed critically, because pigs are quadruped and were maintained prone, due to inherent risks of lung dysfunction when maintained in the supine position for prolonged period of times. Patients are normally maintained in the supine semirecumbent position, and the auto-regulation mechanisms in pulmonary and hemodynamic physiology, which may have played a role in our findings, could be different in pigs and humans. Finally, this study did not encompass the entire range of inflammatory biomarkers that could vary during the course of VAP. For instance, due to methodological limitations of the porcine assay, we did not measure procalcitonin, which was evaluated in previous clinical studies [43]. 


\section{Conclusions}

In conclusion, this experimental study confirms that in an animal model of P. aeruginosa VAP, the Trendelenburg position hampers systemic inflammation through avoidance of VAP. In addition, in this model, culture of tracheal secretions is a precise method to diagnose VAP, with marginal improvement in diagnostic accuracy when systemic IL-10 and TNF- $\alpha$ are assessed concurrently. Further clinical studies will be necessary to confirm these hypothesis-generating results.

\section{Abbreviations}

BAL: Bronchoalveolar lavage; CFU: Colony-forming unit; ETA: Endotracheal aspirate; ETT: Endotracheal tube; ICU: Intensive care unit; IL: Interleukin; MV: Mechanical ventilation; PEEP: Positive end-expiratory pressure; REML: Restricted maximum likelihood; ROC-AUC: Area under the receiver operating curves; TNF: Tumor necrosis factor; TP: Trendelenburg position; VAP: Ventilator-associated pneumonia; WBC: White blood cells

\section{Acknowledgements}

We deeply thank Ignasi Roca and Jordi Vila from the Research and development in clinical molecular parasitology and microbiology, Barcelona Institute for Global Health, Hospital Clínic-Universitat de Barcelona for their support in the microbiology studies. Also, we acknowledge Jose Ramirez from the Department of Pathology, Hospital Clinic, Barcelona, Spain for his support in histology studies.

\section{Funding}

Support was provided by the Institut d'Investigacions Biomèdiques August Pi i Sunyer (IDIBAPS), Ministerio de Ciencia e Innovación (PS09/01249); European Society of Intensive Care Medicine-ESICM (2009 Alain Harf Award on Applied Respiratory Physiology); Fundació Catalana de Pneumologı (FUCAP); Sociedad Española de Neumología y Cirugía Torácica (SEPAR); Centro de Investigación Biomedica En Red-Enfermedades Respiratorias, (CIBERES).

\section{Availability of data and materials}

The datasets used and/or analyzed during the current study are available from the corresponding author on reasonable request.

\section{Authors' contributions}

G Li Bassi had full access to all of the data in the study and takes responsibility for the integrity of the data and the accuracy of the data analysis. He participated to the development of study concept and design, acquisition of data, analysis and interpretation of data, drafting of the manuscript, and statistical analysis; RG Prats participated to the development of study concept and design, acquisition of data, analysis and interpretation of data, and drafting of the manuscript; AA participated to the development of study concept and design, analysis and interpretation of data, and critical revision of the manuscript for important intellectual content; EA participated to the acquisition of data, analysis and interpretation of data, and critical revision of the manuscript for important intellectual content; J-DM participated to the acquisition of data, analysis and interpretation of data, and critical revision of the manuscript for important intellectual content; OTR participated to the acquisition of data, analysis and interpretation of data, statistical analysis, and critical revision of the manuscript for important intellectual content; MR participated to the acquisition of data, analysis and interpretation of data, and critical revision of the manuscript for important intellectual content; LF participated to the acquisition of data, analysis and interpretation of data, and critical revision of the manuscript for important intellectual content and administrative and technical support; AM participated to the acquisition of data, analysis and interpretation of data, and critical revision of the manuscript for important intellectual content and administrative and technical support; AM participated to the acquisition of data, analysis and interpretation of data, and critical revision of the manuscript for important intellectual content and administrative and technical support; NL participated to the acquisition of data, analysis and interpretation of data, and critical revision of the manuscript for important intellectual content and administrative and technical support; MF participated to the acquisition of data, analysis and interpretation of data, and critical revision of the manuscript for important intellectual content; IM-L participated to the acquisition of data, analysis and interpretation of data, and critical revision of the manuscript for important intellectual content; PP participated to the analysis and interpretation of data and critical revision of the manuscript for important intellectual content; DC participated to analysis and interpretation of data and critical revision of the manuscript for important intellectual content; PP participated to the analysis and interpretation of data and critical revision of the manuscript for important intellectual content; and AT participated to the development of study concept and design, analysis and interpretation of data, and critical revision of the manuscript for important intellectual content. All authors read and approved the final manuscript.

\section{Ethics approval and consent to participate}

The Institutional Ethics Committee evaluated and approved our study protocol: Dr. Jordi Alberch Vie; Álvaro Gimeno Sandig; Raquel Corral Vistué; Dr. Garikoitz Azkona Mendoza; Dr. Victor Fernández Dueñas; Dr. Jordi Guinea Mejías; Dr. Francesc López Soriano; Dr. Carmen Navarro Aragay; Dr. Francisco José Pérez Can; Dr. Montserrat Rigol Muixart; and Dr. Teresa Rodrigo Calduch.

\section{Consent for publication}

Not applicable.

\section{Competing interests}

The authors declare that they have no competing interests. 


\section{Publisher's Note}

Springer Nature remains neutral with regard to jurisdictional claims in published maps and institutional affiliations.

\section{Author details}

${ }^{1}$ Division of Animal Experimentation, Department of Pulmonary and Critical Care Medicine, Thorax Institute, Hospital Clinic, Calle Villarroel 170, Esc 6/8 PI 2, Barcelona, Spain. ' Institut d'Investigacions Biomèdiques August Pi i Sunyer (IDIBAPS), Barcelona, Spain. ${ }^{3}$ Centro de Investigación Biomedica En Red- Enfermedades Respiratorias (CIBERES), Barcelona, Spain. ${ }^{4}$ University of Barcelona, Barcelona, Spain. ${ }^{5}$ Pathophysiological Laboratory, Institut de Investigacion Parc Tauli, Corporació Sanitaria Universitaria Parc Tauli, Autonomous University of Barcelona, Sabadell, Barcelona, Spain. ${ }^{6}$ Cardiology Department, Hospital Clinic, Barcelona, Spain. ${ }^{7}$ Dipartimento di Anestesia e Rianimazione, ASST Santi Paolo e Carlo, Dipartimento di Scienza e Salute, Universita degli Studi di Milano, Milan, Italy. ${ }^{8}$ Dipartimento Scienze Chirurgiche e Diagnostiche Integrate (DISC), Università degli Studi di Genova, Genova, Italy. ${ }^{9}$ Multidisciplinary Intensive Care Research Organization (MICRO), Department of Clinical Medicine, Trinity Centre for Health Sciences, St James's University Hospital, Dublin, Ireland. ${ }^{10}$ Polyvalent Intensive Care Unit, São Francisco Xavier Hospital, Centro Hospitalar de Lisboa Ocidental, Lisbon, Portugal. " ${ }^{11}$ NOVA Medical School, CEDOC, New University of Lisbon, Lisbon, Portugal.

Received: 28 June 2018 Accepted: 30 September 2018

Published online: 20 October 2018

\section{References}

1. Fihman V, Messika J, Hajage D et al (2015) Five-year trends for ventilator-associated pneumonia: correlation between microbiological findings and antimicrobial drug consumption. Int J Antimicrob Agents 46:518-525. https://doi.org/10. 1016/j.jijantimicag.2015.07.010

2. Kalil AC, Metersky ML, Klompas M et al (2016) Management of adults with hospital-acquired and ventilator-associated pneumonia: 2016 clinical practice guidelines by the Infectious Diseases Society of America and the American Thoracic Society. Clin Infect Dis 63:e61-e111. https://doi.org/10.1093/cid/ciw353

3. Torres A, Niederman MS, Chastre J et al (2017) International ERS/ESICM/ESCMID/ALAT guidelines for the management of hospital-acquired pneumonia and ventilator-associated pneumonia: Guidelines for the management of hospitalacquired pneumonia (HAP)/ventilator-associated pneumonia (VAP) of the European Respiratory Society (ERS), European Society of Intensive Care Medicine (ESICM), European Society of Clinical Microbiology and Infectious Diseases (ESCMID) and Asociación Latinoamericana del Tórax (ALAT). Eur Respir J 50 doi: https://doi.org/10.1183/13993003.00582-2017

4. Bonten MJ, Froon AH, Gaillard CA et al (1997) The systemic inflammatory response in the development of ventilatorassociated pneumonia. Am J Respir Crit Care Med 156:1105-1113

5. Hillas G, Vassilakopoulos T, Plantza P et al (2010) C-reactive protein and procalcitonin as predictors of survival and septic shock in ventilator-associated pneumonia. Eur Respir J 35:805-811. https://doi.org/10.1183/09031936.00051309

6. Klompas M (2015) Potential strategies to prevent ventilator-associated events. Am J Respir Crit Care Med 192:1420-1430. https://doi.org/10.1164/rccm.201506-1161Cl

7. Torres A, El-Ebiary M, Soler N et al (1996) Stomach as a source of colonization of the respiratory tract during mechanical ventilation: association with ventilator-associated pneumonia. Eur Respir J 9:1729-1735

8. Li Bassi G, Panigada M, Ranzani OT et al (2017) Randomized, multicenter trial of lateral Trendelenburg versus semirecumbent body position for the prevention of ventilator-associated pneumonia. Intensive Care Med 43:1572-1584. https://doi.org/10.1007/s00134-017-4858-1

9. Grover V, Pantelidis P, Soni N et al (2014) A biomarker panel (Bioscore) incorporating monocytic surface and soluble TREM-1 has high discriminative value for ventilator-associated pneumonia: a prospective observational study. PLoS One 9:e109686. https://doi.org/10.1371/journal.pone.0109686

10. Martin-Loeches I, Bos LD, Povoa P et al (2015) Tumor necrosis factor receptor 1 (TNFRI) for ventilator-associated pneumonia diagnosis by cytokine multiplex analysis. Intensive Care Med Exp 3:26. https://doi.org/10.1186/s40635-015-0062-1

11. Póvoa P, Martin-Loeches I, Ramirez P et al (2016) Biomarker kinetics in the prediction of VAP diagnosis: results from the BioVAP study. Ann Intensive Care 6:32. https://doi.org/10.1186/s13613-016-0134-8

12. Douglas IS (2016) New diagnostic methods for pneumonia in the ICU. Curr Opin Infect Dis. https://doi.org/10.1097/QCO. 0000000000000249

13. Li Bassi G, Rigol M, Marti J-DD et al (2014) A novel porcine model of ventilator-associated pneumonia caused by oropharyngeal challenge with Pseudomonas aeruginosa. Anesthesiology 120:1205-1215. https://doi.org/10.1097/ALN. 0000000000000222

14. Li Bassi G, Saucedo L, Marti J-D et al (2012) Effects of duty cycle and positive end-expiratory pressure on mucus clearance during mechanical ventilation*. Crit Care Med 40:895-902. https://doi.org/10.1097/CCM.0b013e318236efb5

15. Benjamin R, Chapman G, Kim C, Sackner M (1989) Removal of bronchial secretions by two-phase gas-liquid transport. Chest 95:658-663. https://doi.org/10.1378/chest.95.3.658

16. Li Bassi G, Zanella A, Cressoni M et al (2008) Following tracheal intubation, mucus flow is reversed in the semirecumbent position: possible role in the pathogenesis of ventilator-associated pneumonia. Crit Care Med 36:518525. https://doi.org/10.1097/01.CCM.0000299741.32078.E9

17. Li Bassi G, Ranzani O, Marti JD, et al (2013) An in vitro study to assess determinant features associated with fluid sealing in the design of endotracheal tube cuffs and exerted tracheal pressures. Crit Care Med 41:518-26. https://doi.org/10. 1097/CCM.0b013e31826a4804

18. Li Bassi G, Marti JD, Saucedo L et al (2014) Gravity predominates over ventilatory pattern in the prevention of ventilatorassociated pneumonia. Crit Care Med 42:e620-e627. https://doi.org/10.1097/CCM.0000000000000487

19. Luna C, Baquero S, Gando S, et al (2007) Experimental severe Pseudomonas aeruginosa pneumonia and antibiotic therapy in piglets receiving mechanical ventilation. Chest 132:523-31. https://doi.org/10.1378/chest.07-0185

20. de Jager W, te Velthuis H, Prakken BJ et al (2003) Simultaneous detection of 15 human cytokines in a single sample of stimulated peripheral blood mononuclear cells. Clin Diagn Lab Immunol 10:133-139. https://doi.org/10.1128/CDLI.10.1. 133-139.2003 
21. Khan SS, Smith MS, Reda D et al (2004) Multiplex bead array assays for detection of soluble cytokines: comparisons of sensitivity and quantitative values among kits from multiple manufacturers. Cytometry B Clin Cytom 61:35-39. https:// doi.org/10.1002/cyto.b.20021

22. Zhu Y, Alapati D, Costa J et al (2014) A comparison of enzyme-linked immunosorbent assay versus multiplex methodology using an \&lt;i\&gt;in Vitro\&lt;/i\&gt; model of pulmonary hypertension and inflammation. J Biomed Sci Eng 07:419-426. https://doi.org/10.4236/jbise.2014.77044

23. Haugen J, Chandyo RK, Brokstad KA et al (2015) Cytokine concentrations in plasma from children with severe and nonsevere community acquired pneumonia. PLoS One 10:e0138978. https://doi.org/10.1371/journal.pone.0138978

24. Gibot S, Cravoisy A, Levy B et al (2004) Soluble triggering receptor expressed on myeloid cells and the diagnosis of pneumonia. N Engl J Med 350:451-458. https://doi.org/10.1056/NEJMoa031544

25. Ramírez P, Ferrer M, Gimeno R et al (2009) Systemic inflammatory response and increased risk for ventilator-associated pneumonia: a preliminary study. Crit Care Med 37:1691-1695. https://doi.org/10.1097/CCM.0b013e31819fec5f

26. Millo JL, Schultz MJ, Williams C et al (2004) Compartmentalisation of cytokines and cytokine inhibitors in ventilatorassociated pneumonia. Intensive Care Med 30:68-74. https://doi.org/10.1007/s00134-003-2060-0

27. Hellyer TP, Morris AC, McAuley DF et al (2015) Diagnostic accuracy of pulmonary host inflammatory mediators in the exclusion of ventilator-acquired pneumonia. Thorax 70:41-47. https://doi.org/10.1136/thoraxjnl-2014-205766

28. Rouby JJ, Martin De Lassale E, Poete P et al (1992) Nosocomial bronchopneumonia in the critically ill. Histologic and bacteriologic aspects. Am Rev Respir Dis 146:1059-1066

29. Fàbregas $\mathrm{N}$, Torres A, El-Ebiary M et al (1996) Histopathologic and microbiologic aspects of ventilator-associated pneumonia. Anesthesiology 84:760-771

30. Panigada M, Berra L, Greco G et al (2003) Bacterial colonization of the respiratory tract following tracheal intubationeffect of gravity: an experimental study. Crit Care Med 31:729-737. https://doi.org/10.1097/01.CCM.0000049943.01252.E5

31. Zanella A, Cressoni M, Epp M et al (2012) Effects of tracheal orientation on development of ventilator-associated pneumonia: an experimental study. Intensive Care Med 38:677-685. https://doi.org/10.1007/s00134-012-2495-2

32. Song Z, Zhang J, Zhang $X$ et al (2015) Interleukin 4 deficiency reverses development of secondary Pseudomonas aeruginosa pneumonia during Sepsis-associated immunosuppression. J Infect Dis 211:1616-1627. https://doi.org/10. 1093/infdis/jiu668

33. Muehlstedt SG, Lyte M, Rodriguez JL (2002) Increased IL-10 production and HLA-DR suppression in the lungs of injured patients precede the development of nosocomial pneumonia. Shock 17:443-450

34. Conway Morris A, Kefala K, Wilkinson TS et al (2010) Diagnostic importance of pulmonary interleukin-1beta and interleukin-8 in ventilator-associated pneumonia. Thorax 65:201-207. https://doi.org/10.1136/thx.2009.122291

35. Schultz MJ, Rijneveld AW, Florquin S et al (2002) Role of interleukin-1 in the pulmonary immune response during Pseudomonas aeruginosa pneumonia. Am J Physiol Lung Cell Mol Physiol 282:L285-L290. https://doi.org/10.1152/ ajplung.00461.2000

36. Gracie JA, Robertson SE, McInnes IB (2003) Interleukin-18. J Leukoc Biol 73:213-224

37. Nakos G, Malamou-Mitsi VD, Lachana A et al (2002) Immunoparalysis in patients with severe trauma and the effect of inhaled interferon-gamma. Crit Care Med 30:1488-1494

38. Leentjens J, Kox M, Koch RM et al (2012) Reversal of immunoparalysis in humans in vivo: a double-blind, placebocontrolled, randomized pilot study. Am J Respir Crit Care Med 186:838-845. https://doi.org/10.1164/rccm.20120406450C

39. Leentjens J, Kox M, van der Hoeven JG et al (2013) Immunotherapy for the adjunctive treatment of sepsis: from immunosuppression to immunostimulation. Time for a paradigm change? Am J Respir Crit Care Med 187:1287-1293. https://doi.org/10.1164/rccm.201301-0036CP

40. Pestka S, Krause CD, Sarkar D et al (2004) Interleukin-10 and related cytokines and receptors. Annu Rev Immunol 22: 929-979. https://doi.org/10.1146/annurev.immunol.22.012703.104622

41. Group CCCT (2006) A randomized trial of diagnostic techniques for ventilator-associated pneumonia. N Engl J Med 355: 2619-2630. https://doi.org/10.1056/NEJMoa052904

42. Manzano F, Fernández-Mondéjar E, Colmenero M et al (2008) Positive-end expiratory pressure reduces incidence of ventilator-associated pneumonia in nonhypoxemic patients. Crit Care Med 36:2225-2231. https://doi.org/10.1097/CCM. Ob013e31817b8a92

43. Duflo F, Debon R, Monneret G et al (2002) Alveolar and serum procalcitonin: diagnostic and prognostic value in ventilator-associated pneumonia. Anesthesiology 96:74-79

\section{Submit your manuscript to a SpringerOpen ${ }^{\circ}$ journal and benefit from:}

- Convenient online submission

- Rigorous peer review

- Open access: articles freely available online

- High visibility within the field

- Retaining the copyright to your article

Submit your next manuscript at $\mathbf{s p r i n g e r o p e n . c o m ~}$ 